\title{
Application of the Fuzzy Optimal Model in the Selection of the Startup Hub
}

\author{
Xinman Zhu $\mathbb{D}^{1},{ }^{1}$ Jie Dai $\mathbb{D}^{2},{ }^{2}$ Haoran Wei $\mathbb{D}^{2},{ }^{2}$ Debing Yang $\mathbb{D}^{3},{ }^{3}$ Weilun Huang ${ }^{\mathbb{D}},{ }^{4}$ \\ and Zhang Yu ${ }^{5}$ \\ ${ }^{1}$ School of Management, Wenzhou Business College, Wenzhou, China \\ ${ }^{2}$ Institute for Advanced Studies, University of Malaya, Kuala Lumpur, Malaysia \\ ${ }^{3}$ School of Economics and Management, Nanjing University of Aeronautics and Astronautics, Nanjing, China \\ ${ }^{4}$ School of Finance and Trade, Wenzhou Business College, Wenzhou, China \\ ${ }^{5}$ Department of Media and Communications, London School of Economics and Political Science, Holborn, UK
}

Correspondence should be addressed to Weilun Huang; drweilunhuang@126.com

Received 15 November 2020; Revised 25 December 2020; Accepted 13 January 2021; Published 4 February 2021

Academic Editor: Jorge E. Macias-Diaz

Copyright ( 92021 Xinman Zhu et al. This is an open access article distributed under the Creative Commons Attribution License, which permits unrestricted use, distribution, and reproduction in any medium, provided the original work is properly cited.

\begin{abstract}
This paper integrates nominal group technique (NGT), analytical hierarchy process (AHP), and fuzzy technique for order preference by similarity to an ideal solution (TOPSIS) approach, and a case study has been used to demonstrate the fuzzy optimal selection model. From a literature review on the startup hub and the interviews conducted with officials and experts, the selection criteria are (1) convenience-promoted by the city's entrepreneurial policies or its traffic infrastructure; (2) potentiality-promoted by a regional network or value chain of startups. Lastly, the best idle land resulted in this case study with equal decision-making power using the fuzzy method is Taipei Jianguo Brewery, and the difference of decision-making power might make the best idle land to be Wanbao Textile Factory.
\end{abstract}

\section{Introduction}

Many cities around the world are actively promoting various aspects of policies of innovation and entrepreneurship. Many works of the literature have proved that the startup hub could help founding startups, launching the successful venture, and upgrading urban economic and political status. Also, many startup hubs help startups in the country get economic or noneconomic assistance from the government, so startup hub policies are an essential part of innovation and entrepreneurship. Based on the literature review, the reason why startup hubs could help startups succeed is as follows: the competitive power of startups might be upgraded by the space and resources, as well as the interactive relations (such as information and communications technology, experts, and customers) in specialized services of the startup hub. Mulas et al. [1] found the entrepreneurship ecosystems (as startup hubs) in cities could maintain competitiveness, reduce poverty, and increase shared prosperity.
To increase competitive advantages of its startups, through startup hubs, Chongqing municipal government provides a variety of subsidies, such as the subsidy of production (up to RMB a million dollars), the subsidy proportion of rent (up to $50 \%$ for 200 square meters), the grant of research and development (RMB 0.5 million dollars, the maximum of a single project), the subsidy of patent maintenance fee (the full amount in three years), the subsidy of enterprise financing (up to RMB a million dollars), the equity investment of the maker (up to $\mathrm{RMB}$ a million dollars), and the startup project support fund (up to RMB two million dollars). Kupp et al. [2], Ledford [3], Katz and Wagner [4], and Bøllingtoft and Ulhøi [5] believed that the functions or values of the startup hub for startups are the space and resource sharing to make cost reduction, the provision of high-impact professional services and capital to make market-entry time reduction, the link of the manufacturer's cooperation network to establish the industry chain, and the alliance or integration on the external networks of startup hubs to accelerate the startup speed. 
Moreover, the economic benefits offered by a startup hub for startups are demand-side economy of scale, the reduction of transaction cost, the spillover effect of spatial knowledge, urban innovation, and collective learning. The demand-side economy of scale can expand the scale of demand and then broaden cooperation in fields such as agriculture, energy, clean energy, and innovation. Due to the regional culture, the mode of production, and the regulations of startup hubs, the reduction of transaction costs can reduce the uncertainty of interaction and cooperation among startups and the transaction cost of the opportunistic behavior or hitchhiker. Tacit knowledge is an intangible cultural resource in the region of startup hubs, which could be thought as its unique spatial knowledge, and its spillover effect could reduce the cost or increase the benefit of startups. Urban innovation and collective learning are the communication and learning networks with the government, participating institutions, or informality, which are established by startup hubs [6].

The economic benefits of startup hubs to cities are their increment upgrading on residents' income, employment, and innovation environment. Frost-Kumpf [7] believed that the advantages of cultural districts, which are now thought to be a startup hub, for the city are as follows: (1) the beautification and activation of urban sightseeing and urban innovation environment; (2) the attraction of employment opportunities, residents, and high knowledge of labor; and (3) the value enhancement of the real estate taxation and mortgage. Also, the startup hubs could improve the status of the city in the global value chains through the interaction of startups, trade, and networks. The points of startup hubs should be the creation of new technologies, products, and markets caused by the integration of many kinds of technologies and industries, such as life sciences, telecommunications, energy, and education [8]. Katz and Wagner [4] believed that the startup hubs in the city could boost economic benefit, status, and jobs and reduce its carbon emissions.

For the advantages of startup hubs, many cities are eager to find suitable idle land which could be converted into startup hubs. From a review of the literature on startup hubs and the result of interviews conducted with experts, the considerations of suitable idle land that could be converted into startup hubs should be its site and architecture. Thus, this paper focuses on the selection process and empirical results on the site of startup hubs across the region, which are fostered by the municipal and local government. People in different countries have different ways of selecting the site of startup hubs. There are two kinds of decision-making party for selecting the site of startup hubs; one party is the private operator of the startup hubs, and the government only needs to make sure that the competition on selecting the site of startup hubs is engaged in a fair and open process, such as the case of the Silicon Valley in the United States. The other is the municipal government and the government-led integration of the space and resources required by startup hubs, such as the Chongqing case in China and the Paris case in France.

This paper cannot find any literature that discussed the site selection of startup hubs fostered by the municipal government. The decision-making process resulting in selecting the best site of idle lands that could be converted into startup hubs is complex, dynamic, and uncertain. Fuzzy TOPSIS should apply it to solve multiple-criteria decision-making problems in an uncertain environment. Therefore, the above decision-making process resulting in the selection of the best idle land in this paper is to use the nominal group technique (NGT) for qualitative and quantitative criteria, the concept of analytical hierarchy process (AHP) for selecting the best idle land, and fuzzy technique for order preference by similarity to an ideal solution (TOPSIS) method which could reduce the risk from these multiple fuzzy criteria.

The purpose of this paper is to propose and elaborate upon a multiple-criteria decision-making (MCDM) approach for the site selection of startup hubs fostered by the municipal government. From the results of the literature review and expert surveys, the selection criteria are its convenience and potentiality. As Loots et al. [9] thought, the ecosystem (like startup hub) has benefitted from social interactions and reciprocity transactions, and its growth and sustainability should be influenced by the city's local demand dynamics, competition for the physical space, gentrification, and policies [10-14].

The remainder of this paper is organized as follows: in Section 2, a summary of the review of the literature and the site selection process of startup hubs fostered by the municipal government are given. The results of a case study are presented in Section 3, focusing on the site selection of the best idle land, which could be converted into startup hubs by the Taipei municipal government of Taiwan. Section 4 concludes our findings and suggests further research.

\section{Literature Review and the Proposed Method}

Combining NGT and AHP with fuzzy TOPSIS provides an integrated process to solve the MCDM problem for site selection of startup hub candidates fostered or supported by the municipal government. The flowchart is shown in Figure 1 [15-20].

Firstly, from Figure 1, an initial list of idle lands in Taipei city that could be used as startup hubs should be compiled from the city government. In addition, startup hub candidates are chosen from the above initial list vetted with the experts who work in the relevant field in Taipei city.

Secondly, NGT was used to create the selection criteria of candidates based on a review of the relevant literature and results of key informant interviews conducted; the site selection decision of the best idle land which could be converted into startup hubs by the municipal government depends on the criteria on the convenience degree and the potential on its site of the idle land. The points of NGT are the join of every decision maker, no opinion leader, and all opinions are judged fairly. Thus, criteria can be divided into two types as convenience criteria $C^{C}$ and potential criteria $C^{P}$. Then, the criteria of this paper are $C=\left\{C_{1}, C_{2}, \ldots, C_{n}\right\}=C^{C} \cup C^{P}$ and $C^{C} \cap C^{P}=\varnothing[21]$.

The convenience degree factor of startup hubs is its convenience, which is promoted by policies or traffic 


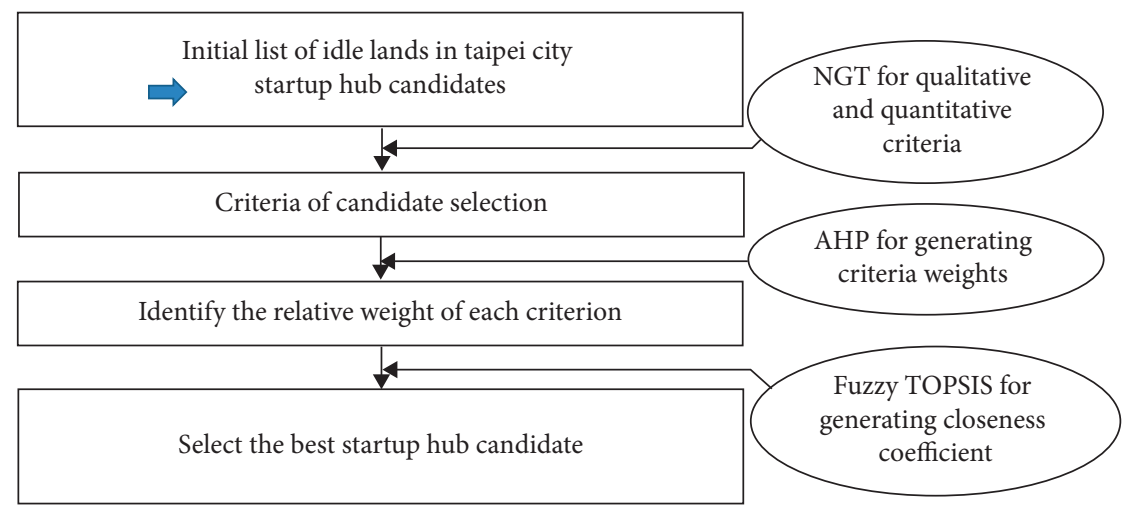

Figure 1: The integration process of site selection across a number of startup hub candidates.

infrastructure $\left(C^{C}=\left\{C_{1}, C_{2}\right\}\right)$. In addition, the potential factor for the site is the potential which is promoted by the regional network and value chains of startups $\left(C^{P}=\left\{C_{3}, C_{4}, C_{5}\right\}\right)$. Therefore, the government should clarify the present situation and consider the future of policy advice, traffic infrastructure, regional network, and value chains (production and marketing stages) of startups on the candidates' site. There are five criteria for the selection of the best candidates as the basis for startups.

Thirdly, the AHP is used to determine each criterion's relative weight based on preferences and subjective judgments of experts. Also, the fuzzy TOPSIS method is used to define the closeness coefficient for the performance of startup hub candidates with respect to each criterion. Chen et al. [22] applied MQCAC and fuzzy TOPSIS to improve the multicriteria decision analysis and the quality of unleaded gasoline.

Last but not least, the fuzzy TOPSIS approach could help to convert the decision makers' preferences and experience into meaningful results for decision makers by applying linguistic values to assess each alternative candidate based on each criterion [23]. Then, the best startup hub has been selected as a candidate.

To explore the second step of site selection's integration process, its optimal site selection criteria of the startup hub should depend on its theoretical and empirical literature. The resource accessibility of the startup hub would influence its competitive advantage and economic performance. The resource-based theory should be able to explain, predict, and examine the phenomena of the startup hub; its points are resource heterogeneity, entrepreneurial cognition, entrepreneurial alertness, market opportunity, coordinated knowledge and firm, ex-post and ex-ante limits to competition, uncertainty, information asymmetries, imperfect factor mobility, and path dependency [24, 25]. On the contrary, a thriving startup hub should have many interactions among startups and their surrounding political, socioeconomic, traffic, industrial, and local cultural environments [13, 14, 26-29].

From the above discussion, the reasons for the criteria of its convenience promoted by the government policy are as follows: (1) the convenience of startup hubs for startups could be promoted by a variety of policies, such as the grand funding, the preferential tax, and the construction of surrounding public facilities, as well as the system of land acquisition. (2) There are more and more policies related to startup hubs, such as supporting them in the innovation policy, adopting a new regional development policy, and applying the industrial policy of a country, as well as policies of small and medium-sized enterprises (SMEs). Also, more policies are related to startup hubs and are more convenient for startups. Brown and Mason [30] thought the policies for startup hubs should be designed to help foster vertical connections across ecosystems. Migendt et al. [31] found the finance-innovation-policy nexus existed.

The reasons for the criteria of its convenience promoted by traffic infrastructures are as follows: (1) the convenience for startups that startup hubs offer could be promoted by many kinds of traffic infrastructures, such as airport, railway station, and bus station, as well as mass rapid transit (MRT) station. (2) Most of these startups come from SMEs and need to make more of an effort to negotiate with customers or develop a new go-to-market field. Therefore, more and more traffic infrastructures around startup hubs in Taipei city make the startups more convenient. Ustinovichius et al. [32] thought the accessibility, transportation costs, and time spent on the road are important for improving business conditions. Katz and Wagner [4] found North Carolina's Research Triangle Park, in November 2012, unveiled a new 50-year master plan that calls for a light rail transit line to connect with the Raleigh-Durham region. Sorenson and Stuart [33] found the geographic and social networks between venture capitals and the startup would affect the identification or support of the startups' performance by venture capitals.

The reasons for the criteria of its potential promoted by the regional network are as follows:

(1) The regional network about education, culture, and service facilities could promote the potential of startup hubs, such as many works of the literature proved the essential factors for the potential of startup hubs which are as follows: A. knowledge spillover effects and spatial interactions on the output of universities and research institutions; B. the culture value of famous landmarks and 
cultural landscapes; C. the living function of convenience stores; D. a large variety of leisure and entertainment places (see [4, 34-36]; [6, 37-41]).

(2) Various startup business programs are mostly related to the cultural and creative industries, for the potential-promoted by the regional network of startup hubs, and many governments would combine startup hubs with cultural and creative facilities $[7,42]$. As Singh and Bala Subrahmanya [43] found, tech startups' financial requirements over their life cycle are their human capital, research capital, and social capital.

The reasons for the criteria of its potential promoted by startups' value chains which were divided with the stages of production and marketing are as follows:

(1) According to Webber and Labaste [44], Kaplinsky and Morris [45], and Chesbrough and Rosenbloom [46], all stages of startups' value chain are production, processing, brand, marketing, as well as logistics, and cross-industry cooperation. Ngugi et al. [47] found that the winning strategic factors responsible for mobile product innovation in the African market should be sustainability and reconfiguration of innovation, strategic assets, and business ecosystem. Geibel and Manickam [48], Herrmann et al. [49], Isenberg [50], and Belussi [6] stated that the startup ecosystem which is similar to a startup value chain would promote the potential of the startup hubs, for startups often lack relationships among customers, suppliers, and related industries. Kritikos [8] found that Berlin-Adlershof research hub is an integrated business, technology, and media park that enjoys a site's advantage by its easy access to scientific research and Berlin's commercial infrastructure.

The members of the startup ecosystem are colleges, startups, accelerators, angel investors (or seed fund), venture capitalists (or crowd-funding), mergers and acquisitions in the banking industry, business partners, and service providers, as well as governments and customers. Vankamamidi [51] found that T-Hub was formed to build a booming startup ecosystem in the country. Baum and Silverman [52] found that alliance, intellectual, and human capital of biotechnology startups are the selection criteria in venture financing and the affecting factors on biotechnology startups' future performance. Hellmann and Puri [53] found venture capitalists could provide financial resources or management expertise to startups. Baum et al. [54] found that the variation in startups' alliance network composition supports their early performance, especially their innovative performance. Walker et al. [55] found strong support for social capital in reproducing the startups' work overtime.
(2) Startup hubs promoted by the governments have the potential to become the influential startup ecosystem, such as Xiantao Big Data Valley of Chongqing in China and Welcome City Lab of Paris in France. The members of the startup ecosystem in Xiantao Big Data Valley include more than 30 leading companies, more than 300 core companies, more than 1000 startups, more than 200 incubations, more than 500 memberships, more than 20 research and development institutions, and more than ten training systems. The members of the startup ecosystem in Welcome City Lab are the incubations, startups, and partners, such as Air France, Amadeus company, Paris Aéroport, and Carlson Wagonlit Travel (CWT), as well as Galeries Lafayette Group [56].

\section{A Case Study of the Site Selection of the Best Idle Land Which Could Be Converted into Startup Hubs by the Municipal Government}

The decision-making group (DMG, seven experts) consists of a government officer $\left(D_{1}\right)$, two experts of the startup hub $\left(D_{2}\right.$ and $\left.D_{3}\right)$, and four startups $\left(D_{4}, D_{5}, D_{6}\right.$, and $\left.D_{7}\right)$ who are invited to participate in providing a range of opinions based on their judgment. With the review of the Taipei municipal government, this paper obtains an initial list of more than ten idle lands. The Taipei municipal government would like to select the best idle land which could be converted into startup hubs, and hub candidates resulted from the initial list of idle lands vetted by the DMG are Jianguo Brewery $\left(V_{1}\right)$, Wanbao Textile Factory $\left(V_{2}\right)$, and Minglun Elementary School $\left(V_{3}\right)$.

To select the best idle land which could be converted into startup hubs, the candidates could be determined as follows: (1) $C_{1}$ (policy): its convenience promoted by government's policy, (2) $\mathrm{C}_{2}$ (traffic infrastructure): its convenience promoted by traffic infrastructure, (3) $C_{3}$ (regional network): its potential promoted by the regional network, (4) $C_{4}$ (value chain (production stages)): its potential promoted by the production stages of startups' value chain, and $(5) C_{5}$ (value chain (marketing stages)): its potential promoted by the marketing stages of startups' value chain. The hierarchical and sequential structure of group decision-making is presented in Figure 2.

As an illustrative example, five experts presented their points of view for site selection by linguistic variables to assess the weight that reflects the importance of criteria, and the matrix of triangular fuzzy numbers and fuzzy preference used in experts for linguistic variables [very low; low; fairly low; fairly high; high; very high $]$ are $[(0,0$, $0.2)$; $(0,0.2,0.4) ;(0.2,0.4,0.6) ;(0.4,0.6,0.8) ;(0.6,0.8$, $1.0) ;(0.8,1.0,1.0)]$. Moreover, the linguistic variables of fuzzy ratings for the alternative's preference are from Figure 3. In Figure 3, a triangular fuzzy number can be defined as a triplet $(\alpha, \beta, \gamma)$; the utility function $\left(u_{\delta}(x)\right)$ of the fuzzy rating $\delta$ is defined as [57] 


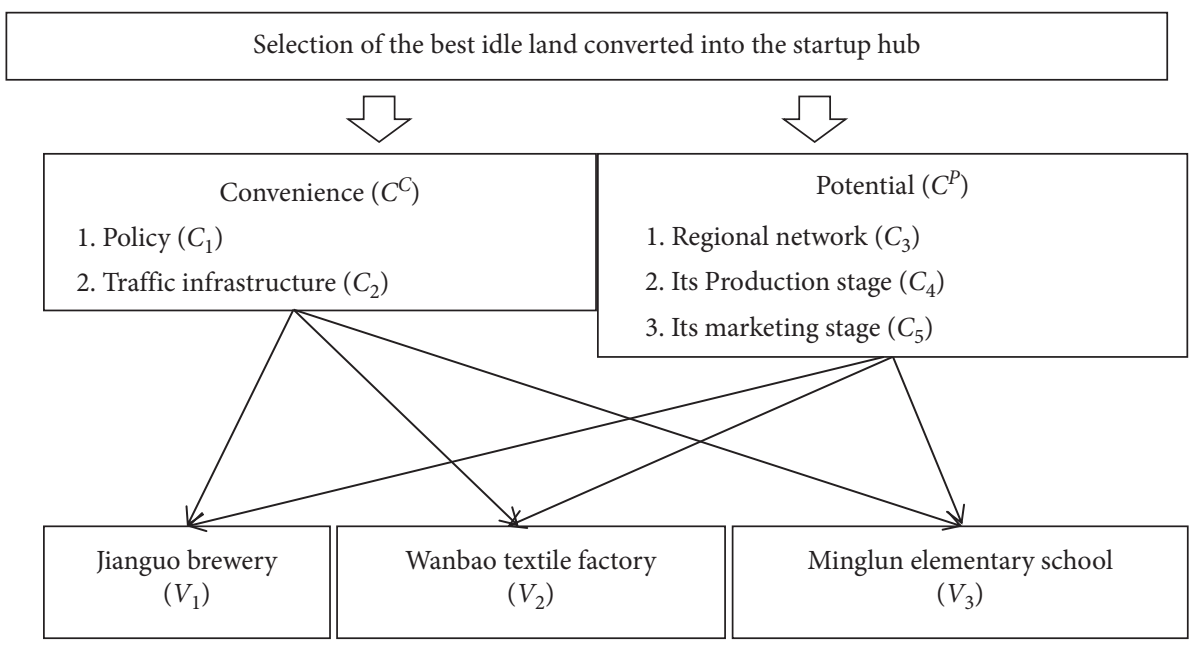

FIGURE 2: Hierarchy structure of the selection for the startup hub.

$$
u_{\delta}(x)= \begin{cases}\frac{(x-\alpha)}{(\beta-\alpha)}, & x \in[\alpha, \beta], \\ \frac{(\gamma-x)}{(\gamma-\beta)}, & x \in[\beta, \gamma], \\ 0, & \text { otherwise }\end{cases}
$$

where $\alpha \leq \beta \leq \gamma$.

The fuzzy weights of evaluation criteria generally determined by the seven experts are shown in Table 1. In addition, the seven experts use linguistic variables in order to evaluate the fuzzy preference rating of each candidate with respect to each criterion. The rating is shown in Table 2. Furthermore, the linguistic variables for the importance of each criterion's fuzzy weights are similar to Figure 3.

So far, most works of the literature on the MCDM problem have assumed the weight of each decision maker is the same in their selection model. In a practical case, this is rarely true. By referring to the site selection of the startup hub as an example, the government will most likely have the most authority and influence power in the decision. Therefore, two selection models have been discussed in this paper. Following most historical studies, case one assumes that the weight of decision-making power for each decision maker is equal. Case two considers that the government has half of the decisionmaking power, and then, the rest of the decision makers equally shared the remaining half.

SMEs' innovation and industrial policies for all candidates are the same. The regional development policies are different for Wanbao Textile Factory and Minglun Elementary School. However, from a regional development perspective, there is no single regional development policy for Jianguo Brewery. The time-efficient (by car or on foot) orders from startup hub candidates to traffic infrastructures are Minglun Elementary School, Wanbao Textile Factory, and Jianguo Brewery (from the biggest to the smallest). Based on the number of education services, culture and

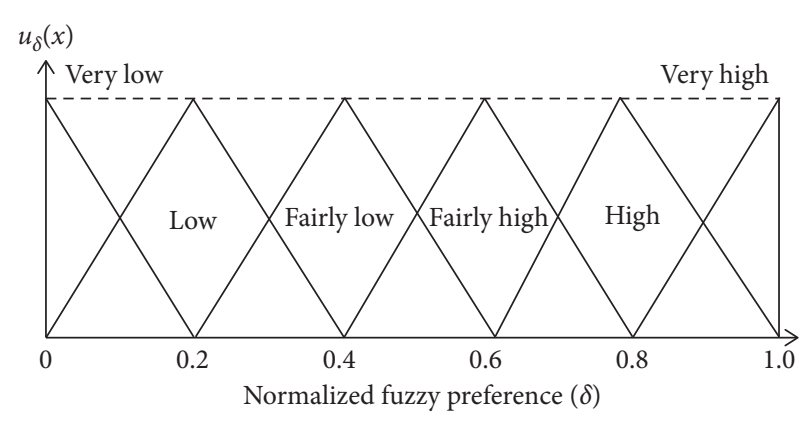

FIgURE 3: The linguistic variables of fuzzy ratings for the alternative's preference.

recreation, and service facilities within 1 kilometer of candidates, the candidates' order on their regional network's promoted potential is Jianguo Brewery, Wanbao Textile Factory, and Minglun Elementary School (from the biggest to the smallest). For Jianguo Brewery, other value chains for the tourism industry, digital industry, creative industry, and the neighboring Taipei area are quite far away. For Wanbao Textile Factory and Minglun Elementary School, the tourism supply chain exists in the neighboring area; however, there are no startup's auxiliary industries, such as intellectual property, law, and accounting. The fuzzy preference structure is shown in Table 2.

The weights of each criterion summarized in Table 1 and the fair consistency evaluation in fuzzy preference relations for policy subjects by experts summarized in Table 2 are used to create a fuzzy weighted decision matrix, which is shown in Table 3. The data of Table 3 are from $V^{*}=\left[\left(\max _{i} \tilde{v_{i j}}\right)\right.$ $\left.j \in J),\left(\min _{i} \tilde{v_{i j}} \mid j \in J\right)\right]$ and $V^{-}=\left[\left(\max _{i} \tilde{v_{i j}} \mid j \in J\right),\left(\min _{i} \tilde{v_{i j}} \mid\right.\right.$ $j \in J)$ ], and the fuzzy positive ideal and fuzzy negative ideal are determined as

$$
\begin{aligned}
V^{*}= & {[(1,1,1),(1,1,1),(1,1,1),(0.04,0.04,0.04),(1,1,1)], } \\
V^{-}= & {[(0.16,0.16,0.16),(0.16,0.16,0.16),(0.12,0.12,0.12),} \\
& \cdot(0.8,0.8,0.8),(0.08,0.08,0.08)] .
\end{aligned}
$$


TABle 1: The fuzzy weight of criteria from seven experts.

\begin{tabular}{lcccrr}
\hline & $C_{1}$ & $C_{2}$ & $C_{3}$ & $C_{4}$ & $C_{5}$ \\
\hline$D_{1}$ & $(0.8,1.0,1.0)$ & $(0.2,0.4,0.6)$ & $(0.6,0.8,1.0)$ & $(0.4,0.6,0.8)$ & $(0.4,0.6,0.8)$ \\
$D_{2}$ & $(0.6,0.8,1.0)$ & $(0.4,0.6,0.8)$ & $(0.4,0.6,0.8)$ & $(0.4,0.6,0.8)$ & $(0.8,1.0,1.0)$ \\
$D_{3}$ & $(0.6,0.8,1.0)$ & $(0.4,0.6,0.8)$ & $(0.4,0.6,0.8)$ & $(0.4,0.6,0.8)$ & $(0.8,1.0,1.0)$ \\
$D_{4}$ & $(0.4,0.6,0.8)$ & $(0.4,0.6,0.8)$ & $(0.6,0.8,1.0)$ & $(0.6,0.8,1.0)$ & $(0.6,0.8,1.0)$ \\
$D_{5}$ & $(0.4,0.6,0.8)$ & $(0.4,0.6,0.8)$ & $(0.6,0.8,1.0)$ & $(0.6,0.8,1.0)$ & $(0.6,0.8,1.0)$ \\
$D_{6}$ & $(0.6,0.8,1.0)$ & $(0.2,0.4,0.6)$ & $(0.6,0.8,1.0)$ & $(0.4,0.6,0.8)$ & $(0.8,1.0,1.0)$ \\
$D_{7}$ & $(0.6,0.8,1.0)$ & $(0.2,0.4,0.6)$ & $(0.6,0.8,1.0)$ & $(0.6,0.8,1.0)$ & $(0.8,1.0,1.0)$ \\
Fuzzy weight (case 1) & $(0.40,0.76,1.00)$ & $(0.20,0.50,0.80)$ & $(0.40,0.74,1.00)$ & $(0.40,0.68,1.00)$ & $(0.40,0.87,1.00)$ \\
Fuzzy weight (case 2) & $(0.40,0.85,1.00)$ & $(0.20,0.46,0.80)$ & $(0.40,0.76,1.00)$ & $(0.40,0.64,1.00)$ & $(0.40,0.75,1.00)$ \\
\hline
\end{tabular}

TABLE 2: Fuzzy preferences for the three candidates by seven experts using various criteria.

\begin{tabular}{lccccc}
\hline & $F_{1}$ & $F_{2}$ & $F_{3}$ & $F_{4}$ & $F_{5}$ \\
\hline$V_{1}$ & $(0.6,0.8,1.0)$ & $(0.8,1.0,1.0)$ & $(0.6,0.8,1.0)$ & $(0.8,1.0,1.0)$ & $(0.8,1.0,1.0)$ \\
$V_{2}$ & $(0.8,1.0,1.0)$ & $(0.6,0.8,1.0)$ & $(0.6,0.8,1.0)$ & $(0.4,0.6,0.8)$ & $(0.4,0.6,0.8)$ \\
$V_{3}$ & $(0.6,0.8,1.0)$ & $(0.4,0.6,0.8)$ & $(0.8,1.0,1.0)$ & $(0.4,0.6,0.8)$ & $(0.4,0.6,0.8)$ \\
\hline
\end{tabular}

Table 3: Fuzzy weighted decision matrix.

\begin{tabular}{ccccccc}
\hline & & $F_{1}$ & $F_{2}$ & $F_{3}$ & $F_{4}$ & $F_{5}$ \\
\hline \multirow{3}{*}{ Case 1} & $V_{1}$ & $(0.24,0.61,1.00)$ & $(0.16,0.50,0.80)$ & $(0.24,0.59,1.00)$ & $(0.32,0.68,1.00)$ & $(0.32,0.87,1.00)$ \\
& $V_{2}$ & $(0.32,0.76,1.00)$ & $(0.12,0.40,0.80)$ & $(0.24,0.59,1.00)$ & $(0.16,0.41,0.80)$ & $(0.16,0.52,0.80)$ \\
& $V_{3}$ & $(0.24,0.61,1.00)$ & $(0.08,0.30,0.64)$ & $(0.32,0.74,1.00)$ & $(0.16,0.41,0.80)$ & $(0.16,0.52,0.80)$ \\
\hline \multirow{3}{*}{ Case 2 } & $V_{1}$ & $(0.24,0.68,1.00)$ & $(0.16,0.46,0.80)$ & $(0.24,0.61,1.00)$ & $(0.32,0.64,1.00)$ & $(0.32,0.75,1.00)$ \\
& $V_{2}$ & $(0.32,0.85,1.00)$ & $(0.12,0.37,0.80)$ & $(0.24,0.61,1.00)$ & $(0.16,0.39,0.80)$ & $(0.16,0.45,0.80)$ \\
& $V_{3}$ & $(0.24,0.68,1.00)$ & $(0.08,0.27,0.64)$ & $(0.32,0.76,1.00)$ & $(0.16,0.39,0.80)$ & $(0.16,0.45,0.80)$ \\
\hline
\end{tabular}

In two cases, the shortest distance from the fuzzy positive ideal solution (FPIS, $\left.d\left(V_{i}, V^{*}\right), i=1,2,3\right)$ and the farthest distance from the fuzzy negative ideal solution (FNIS, $\left.d\left(V_{i}, V^{-}\right), i=1,2,3\right)$ can be determined by using the method of Zhang et al. (2011). The distance of each candidate from FPIS and FNIS is calculated with respect to the criterion, respectively; using $d_{i}^{*}=\sum_{j=1}^{n} d\left(\widetilde{v}_{i j}, \widetilde{v}_{j}^{+}\right)$and $d_{i}^{-}=\sum_{j=1}^{n} d\left(\widetilde{v}_{i j}, \widetilde{v}_{j}^{-}\right)$, the distance of each candidate's fuzzy positive ideal and fuzzy negative ideal can be calculated with respect to each criterion, respectively, as shown in Table 4.

In case 1 , the closeness coefficient $\left(C C_{i}=d_{i}^{-} /\left(d_{i}^{*}+d_{i}^{-}\right)\right.$, $i=1,2,3)$ for each candidate is calculated as $C C_{1}=0.502$, $C C_{2}=0.501$, and $C C_{3}=0.484$. The alternatives are ranked by $C C_{i}^{*}$, and the results are $V_{1}>V_{2}>V_{3}$. Therefore, some measures are based on quantitative criteria; the best idle land which could be converted into startup hubs, in this case, is Jianguo Brewery. In case 2, each candidate's closeness coefficient is calculated as $C C_{1}=0.500, C C_{2}=0.502$, and $C C_{3}=0.485$, and the results are $V_{2}>V_{1}>V_{3}$. Therefore, the difference of decision-making power might make the best idle land which could be converted into startup hubs to be Wanbao Textile Factory.
TABLE 4: Distance between $V_{i}(i=1,2,3)$ and $V^{*}\left(V^{-}\right)$with respect to each candidate.

\begin{tabular}{ccccccc}
\hline & & $F_{1}$ & $F_{2}$ & $F_{3}$ & $F_{4}$ & $F_{5}$ \\
\hline & $d\left(V_{1}, V^{*}\right)$ & 0.494 & 0.575 & 0.499 & 0.649 & 0.399 \\
& $d\left(V_{2}, V^{*}\right)$ & 0.416 & 0.625 & 0.499 & 0.459 & 0.569 \\
Case 1 & $d\left(V_{3}, V^{*}\right)$ & 0.494 & 0.698 & 0.421 & 0.459 & 0.569 \\
& $d\left(V_{1}, V^{-}\right)$ & 0.654 & 0.420 & 0.614 & 0.308 & 0.643 \\
& $d\left(V_{2}, V^{-}\right)$ & 0.712 & 0.396 & 0.614 & 0.434 & 0.425 \\
& $d\left(V_{3}, V^{-}\right)$ & 0.654 & 0.293 & 0.667 & 0.434 & 0.425 \\
\hline \multirow{5}{*}{ Case 2 } & $d\left(V_{1}, V^{*}\right)$ & 0.476 & 0.589 & 0.493 & 0.638 & 0.419 \\
& $d\left(V_{2}, V^{*}\right)$ & 0.402 & 0.637 & 0.493 & 0.454 & 0.592 \\
& $d\left(V_{3}, V^{*}\right)$ & 0.476 & 0.708 & 0.416 & 0.454 & 0.592 \\
& $d\left(V_{1}, V^{-}\right)$ & 0.677 & 0.408 & 0.620 & 0.313 & 0.599 \\
& $d\left(V_{2}, V^{-}\right)$ & 0.744 & 0.389 & 0.620 & 0.440 & 0.405 \\
& $d\left(V_{3}, V^{-}\right)$ & 0.677 & 0.289 & 0.676 & 0.440 & 0.405 \\
\hline
\end{tabular}

\section{Conclusion}

From the results of the literature review, expert survey, and the above discussion, this paper can come to the conclusion that the site selection of startup hubs is important for startups, the government, and researchers. Therefore, this 
paper focuses on the decision-making of the optimal site selection of startup hubs fostered by the municipal government. There are higher levels of uncertainty and complexity for the decision-making process resulting in the selection of policy subjects. Therefore, how to choose the best startup hub from candidates (i.e., idle lands) in the Taipei municipal government is an MCDM problem.

There are lots of idle lands in Taipei city that could be converted into startup hubs, but there is little literature about case studies on the subjects of the hub site consideration. As there is little literature on this topic, further investigation would be needed. According to the relevant provisions of the domestic and foreign-related cases, the literature review, and the result of interviews conducted with experts, the criteria for the selection of site candidates for startup hubs are its convenience promoted by the government's policy or traffic infrastructure and its potential promoted by the regional network or value chains of startups.

The satisfied idle land which could be converted into startup hubs is found by the integrated approach of NGT, AHP, and fuzzy TOPSIS method to assist decision makers' selection according to their preferences and resource limitations. In the end, the best idle land resulted in this case study with equal decision-making power is Jianguo Brewery, and the difference of decision-making power might make the best idle land to be Wanbao Textile Factory. The potential (the regional network and value chains of startups) for startup hubs of Jianguo Brewery is excellent. Also, the convenience (policy and traffic infrastructure) for startup hubs of Wanbao Textile Factory is superior. In addition, for startup hubs of Minglun Elementary School, its evaluations of potential and convenience are best for it is in the medial position of the city.

More precisely, this paper's contribution and the managerial insights are as follows: (1) the supplement on the literature of a startup hub, which is its optimal site selection: this paper first finds out that the existing literature lacks details on the municipal government's startup hub site selection. Although some existing literature and documents are discussing related issues of startup hubs, there is little empirical literature on the investigation of criteria to choose the best idle land which could be converted into startup hubs. (2) The empirical practice of the method to select the best idle land which could be converted into the startup hub: based on the sample of Taipei's idle lands, this paper summarizes and confirms the site selection, further expands the empirical research in this field, and provides the method and result of Taipei's best idle land, which could be converted into the startup hub.

This paper also stresses the research limitations and provides a useful recommendation for future research. This paper also provides thinking that the site selection consideration of startup hubs is an MCDM problem. To deal with the issues of fuzzy evaluation process among criteria, such as its uncertain factors, its discrimination factors, and its feedback and internal dependency, the future research of the MCDM method based on fuzzy theory, ARAS, and MCGP would make the evaluation results more accurate. Finally, this paper provides the best idle land that could be converted into startup hubs for the Taipei municipal government.

As this paper suggested, the MCGP formulation can be defined as the following:

$$
\begin{array}{ll}
\text { Min } & \sum_{i=1}^{n} w_{i}\left[\left(d_{i}^{+}+d_{i}^{-}\right)+\left(e_{i}^{+}+e_{i}^{-}\right)\right] \\
\text {s.t. } & f_{i}(X)-d_{i}^{+}+d_{i}^{-}=g_{i, 1} \text { or } g_{i, 2} \text { or } g_{i, m}, \quad i=1,2, \ldots, n \\
& g_{i}-e_{i}^{+}+e_{i}^{-}=g_{i, \max }, \quad i=1,2, \ldots, n \\
& g_{i, \max } \geq g_{i} \geq g_{i, \min }, \quad i=1,2, \ldots, n \\
& d_{i}^{+}, d_{i}^{-}, e_{i}^{+}, e_{i}^{-} \geq 0, \quad i=1,2, \ldots, n, \\
& X \in F(F \text { is a feasible set }),
\end{array}
$$

where $g_{i j}(i=1,2, \ldots, n$ and $j=1,2, \ldots, m)$ is the $j$ th aspiration level of the $i$ th goal, $w_{i}$ represents the weight attached to the deviation, and $d_{i}$ is the deviation from the target value $g_{i} ; d_{i}^{+}=\max \left(0, f_{i}(x)-g_{i}\right)$ and $d_{i}^{-}=\max \left(0, g_{i}-f_{i}(x)\right)$ denote over- and underachievement of the $i$ th goal, respectively. In addition, $e_{i}^{+}$and $e_{i}^{-}$are positive and negative deviations attached to $\left|g_{i}-g_{i, \max }\right| ; g_{i, \text { min }}$ and $g_{i, \max }$ are, respectively, lower and upper bounds of $g_{i}$.

Future research could focus on the reaction potential of large-scale emergency incidents, which should be included in startup hubs' site selection criteria, such as coronavirus (COVID-19). Rowan and Galanakis [58] thought COVID19 might help cross-cutting disruption in agri-food, ICT, health, and environment. On the contrary, future research could study the impacts of startup hubs on the socioeconomic environment of the city. Rowan and Galanakis [58] thought that startup hubs have the potential to accelerate the socioeconomic recovery of the city.

Future research could focus on the optimal site selection process of the startup hub, which might be different in different industries, regions, or entrepreneurs. Malecki [14] thought the entrepreneurial ecosystem might be appropriate only for the region with a critical mass of startups. Spigel and Harrison [27] thought that entrepreneurs might be excluded from some local socioeconomic networks for their gender, race, age, or education level.

\section{Data Availability}

Requests for access to the data used to support the findings of this study should be made to Weilun Huang (drweilunhuang@126.com).

\section{Conflicts of Interest}

The authors declare that they have no conflicts of interest.

\section{Acknowledgments}

This research was supported by the Research Project of Zhejiang Federation of Social Sciences of China (no. 
2021N101), Wenzhou Philosophy and Social Science Planning Project (no. 20wsk095), and Basic Scientific Research Projects of Wenzhou Science and Technology Bureau in 2020 (no. R2020007).

\section{References}

[1] V. Mulas, M. Minges, and H. Applebaum, "Boosting tech innovation: ecosystems in cities: a framework for growth and sustainability of urban tech innovation ecosystems," Innovations: Technology, Governance, Globalization, vol. 11, no. 12, pp. 98-125, 2016.

[2] M. Kupp, M. Marval, and P. Borchers, "Corporate accelerators: fostering innovation while bringing together startups and large firms," Journal of Business Strategy, vol. 38, no. 6, pp. 47-53, 2017.

[3] H. Ledford, "Start-ups fight for a place in Boston's biotech hub," Nature, vol. 522, no. 7555, pp. 138-139, 2015.

[4] B. Katz and J. Wagner, "The rise of innovation districts: a new geography of innovation in america," 2014.

[5] A. Bøllingtoft and J. P. Ulhøi, "The networked business incubator-leveraging entrepreneurial agency?" Journal of Business Venturing, vol. 20, no. 2, pp. 265-290, 2005.

[6] F. Belussi, "Policies for the development of knowledge-intensive local production systems," Cambridge Journal of Economics, vol. 23, no. 6, pp. 729-747, 1999.

[7] H. A. Frost-Kumpf, Cultural Districts: The Art as a Strategy for Revitalizing Our Cities, Americans for the Arts, Washington, D. C., USA, 1998.

[8] A. S. Kritikos, A Hub for Startups but not (yet) for FastGrowing Companies, German Institute for Economic Research, Berlin, Germany, 2016.

[9] E. Loots, M. Neiva, L. Carvalho, and M. Lavanga, "The entrepreneurial ecosystem of cultural and creative industries in Porto: a sub-ecosystem approach," Growth and Change, vol. 3, pp. 1-22, 2020.

[10] M. Lavanga, "Cultural districts," in Handbook of Cultural Economics, R. Towse and T. Navarrete, Eds., pp. 174-182, Edward Elgar Publishing, London, UK, 3rd edition, 2020.

[11] M. Lavanga, E. Loots, A. Konomi, V. Avdikos, and E. Iliopoulou, "Creative entrepreneurship and urban space: exploring the location preferences of creative professionals in athens during the economic recession," The Greek Review of Social Research (Special Issue "Work in the Aftermath of the Global Economic Crisis: New Spaces and Types of Work Emerging in Cities of Recession"), vol. 153, pp. 5-36, 2020.

[12] J. Merkel, “"Freelance isn't free.” Co-working as a critical urban practice to cope with informality in creative labour markets," Urban Studies, vol. 56, no. 3, pp. 526-547, 2019.

[13] D. Audretsch, C. Mason, M. P. Miles, and A. O'Connor, “The dynamics of entrepreneurial ecosystems," Entrepreneurship \& Regional Development, vol. 30, no. 3-4, pp. 471-474, 2018.

[14] E. J. Malecki, "Entrepreneurship and entrepreneurial ecosystems," Geography Compass, vol. 12, no. 3, p. e12359, 2018.

[15] Z. K. Öztürk and Ş. Toptanci, “An integrated MCDM model for occupational safety specialist selection," Journal of Business Research-Turk, vol. 9, no. 4, pp. 419-435, 2017.

[16] K.-H. Chen, C.-N. Liao, and L.-C. Wu, "A selection model to logistic centers based on TOPSIS and MCGP methods: the case of airline industry," Journal of Applied Mathematics, vol. 2014, p. 1, 2014.

[17] Y. F. Chang and H. ISHII, "Probing the implementation of project management office by using DEMATEL with a hybrid
MCDM model," Journal of Japan Society for Fuzzy Theory and Intelligent Informatics, vol. 25, no. 6, pp. 935-948, 2013.

[18] X. Zhang, "Venture capital investment selection decision-making base on fuzzy theory," Physics Procedia, vol. 25, pp. 1369-1375, 2012.

[19] C.-N. Liao and H.-P. Kao, "Supplier selection model using taguchi loss function, analytical Hierarchy process and multi-choice goal programming," Computers \& Industrial Engineering, vol. 58, no. 4, pp. 571-577, 2010.

[20] S. Önü and S. Soner, "Transshipment site selection using AHP and TOPSIS approaches under fuzzy environment," Waste Management, vol. 28, no. 9, pp. 1552-1559, 2008.

[21] C. N. Liao, "An evaluation model using fuzzy TOPSIS and goal programming for TQM consultant selection," Journal of Testing and Evaluation, vol. 41, no. 1, pp. 122-130, 2013.

[22] K.-S. Chen, C.-H. Hsu, L.-Y. Ouyang, and C.-M. Yang, "Applying MQCAC and fuzzy TOPSIS to improve the unleaded gasoline quality," Journal of Testing and Evaluation, vol. 45, no. 3, pp. 20150426-20151057, 2017.

[23] W. Huang and Q. Zhang, "Selecting the optimal economic crop in minority regions with the criteria about soil and water conservation," Agricultural Water Management, vol. 241, p. 106295, 2020.

[24] J. Barney and S. A. Alvarez, "Resource-based theory and the entrepreneurial firm," Strategic Entrepreneurship: Creating a New Mindset, vol. 2, pp. 87-105, 2017.

[25] R. S. Nason and J. Wiklund, "An assessment of resource-based theorizing on firm growth and suggestions for the future," Journal of Management, vol. 44, no. 1, pp. 1-29, 2015.

[26] E. Stam and A. van de Ven, "Entrepreneurial ecosystem elements," Small Business Economics, vol. 12, pp. 1-24, 2019.

[27] B. Spigel and R. Harrison, "Toward A process theory of entrepreneurial ecosystems," Strategic Entrepreneurship Journal, vol. 12, no. 1, pp. 151-168, 2018.

[28] Z. J. Acs, E. Stam, D. B. Audretsch, and A. O'Connor, "The lineages of the entrepreneurial ecosystem Approach," Small Business Economics, vol. 49, no. 1, pp. 1-10, 2017.

[29] J. Alvedalen and R. Boschma, "A critical review of entrepreneurial ecosystems research: towards A future research agenda," European Planning Studies, vol. 25, no. 6, pp. 887-903, 2017.

[30] R. Brown and C. Mason, "Looking inside the spiky bits: a critical review and conceptualisation of entrepreneurial ecosystems," Small Business Economics, vol. 49, no. 1, pp. 11-30, 2017.

[31] M. Migendt, F. Polzin, F. Schock, F. A. Täube, and P. von Flotow, "Beyond venture capital: an exploratory study of the finance-innovation-policy nexus in cleantech," Industrial and Corporate Change, vol. 26, no. 6, pp. 973-996, 2017.

[32] L. Ustinovichius, A. Komarovska, and R. Komarovski, "Methods of determining the region's investment strategy," Procedia Engineering, vol. 182, pp. 732-738, 2017.

[33] O. Komarovski and T. E. Stuart, "Syndication networks and the spatial distribution of venture capital investments," American Journal of Sociology, vol. 106, no. 6, pp. 1546-1588, 2001.

[34] R. Florida and C. Mellander, "Rise of the startup city," California Management Review, vol. 59, no. 1, pp. 14-38, 2016.

[35] J. Youtie and P. Shapira, "Building an innovation hub: a case study of the transformation of university roles in regional technological and economic development," Research Policy, vol. 37, no. 8, pp. 1188-1204, 2008.

[36] M. Gittelman, "Does geography matter for science-based firms? Epistemic communities and the geography of research 
and patenting in biotechnology," Organization Science, vol. 18, no. 4, pp. 724-741, 2007.

[37] M. Fritsch and V. Slavtchev, "Universities and innovation in space," Industry and Innovation, vol. 14, no. 2, pp. 201-218, 2007.

[38] M. M. Fischer and A. Varga, "Spatial knowledge spillovers and university research: evidence from Austria," The Annals of Regional Science, vol. 37, no. 2, pp. 303-322, 2003.

[39] L. Anselin, A. Varga, and Z. Acs, "Local geographic spillovers between university research and high technology innovations," Journal of Urban Economics, vol. 42, no. 3, pp. 422-448, 1997.

[40] M. P. Feldman and R. Florida, "The geographic sources of innovation: technological infrastructure and product innovation in the United States," Annals of the Association of American Geographers, vol. 84, no. 2, pp. 210-229, 1994.

[41] A. Jaffe, "Real effect of academic research," The American Economic Review, vol. 79, no. 5, pp. 957-970, 1989.

[42] F. Moulaert and F. Sekia, "Territorial innovation models: a critical survey," Regional Studies, vol. 37, no. 3, pp. 289-302, 2003.

[43] S. Singh and M. H. Bala Subrahmanya, "The financial requirements of tech startups over its lifecycle in Bangalore: an analysis of why and how do they differ?" International Journal of Finance \& Economics, vol. 2020, pp. 1-19, 2020.

[44] C. M. Webber and P. Labaste, Building Competitiveness in Africa's Agriculture: A Guide to Value Chain Concepts and Applications, World Bank Publications, Washington, DC, USA, 2009.

[45] R. Kaplinsky and M. Morris, "A handbook for value chain research," 2001.

[46] H. Chesbrough and R. S. Rosenbloom, "The role of the business model in capturing value from innovation: evidence from Xerox Corporation's technology spin-off companies," Industrial and Corporate Change, vol. 11, no. 3, pp. 529-555, 2002.

[47] B. K. Ngugi, E. A. Elliot, and C. Blankson, "Toward a conceptual framework explaining the strategic factors responsible for mobile product innovation success in an emerging african market," Thunderbird International Business Review, vol. 11, 2020.

[48] R. C. Geibel and M. Manickam, "Comparison of selected startup ecosystems in Germany and in the USA explorative analysis of the startup environments," GSTF Journal on Business Review (GBR), vol. 4, no. 3, 2016.

[49] B. L. Herrmann, J. F. Gauthier, D. Holtschke, R. Berman, and M. Marmer, "The global startup ecosystem ranking 2015," 2015.

[50] D. Isenberg, “The entrepreneurship ecosystem strategy as a new paradigm for economic policy: principles for cultivating entrepreneurship," 2011.

[51] V. K. Vankamamidi, "A conceptual study on startups and T-hubs," Journal Advances in Business Management, vol. 3, no. 2, pp. 71-73, 2017

[52] J. A. C. Baum and B. S. Silverman, "Picking winners or building them? Alliance, intellectual, and human capital as selection criteria in venture financing and performance of biotechnology startups," Journal of Business Venturing, vol. 19, no. 3, pp. 411-436, 2004.

[53] T. Hellmann and M. Puri, "Venture capital and the professionalization of start-up firms: empirical evidence," The Journal of Finance, vol. 57, no. 1, pp. 169-197, 2002.

[54] J. A. C. Baum, T. Calabrese, and B. S. Silverman, "Don't go it alone: alliance network composition and startups' performance in Canadian biotechnology," Strategic Management Journal, vol. 21, no. 3, pp. 267-294, 2000.

[55] G. Walker, B. Kogut, and W. Shan, "Social capital, structural holes and the formation of an industry network," Organization Science, vol. 8, no. 2, pp. 109-125, 1997.

[56] Y. Zheng, J. Liu, and G. George, "The dynamic impact of innovative capability and inter-firm network on firm valuation: a longitudinal study of biotechnology start-ups," Journal of Business Venturing, vol. 25, no. 6, pp. 593-609, 2010.

[57] C. Liao, "Fuzzy analytical hierarchy process and multi-segment goal programming applied to new product segmented under price strategy," Computers and Industrial Engineering, vol. 61 , no. 3, pp. 831-841, 2011.

[58] N. J. Rowan and C. M. Galanakis, "Unlocking challenges and opportunities presented by covid-19 pandemic for cross-cutting disruption in agri-food and green deal innovations: quo vadis?" Science of The Total Environment, vol. 748, 2020. 